\title{
The cycle of fifths
}

\section{Paul C Adams MD, Editor-in-Chief}

$\mathrm{T}$ o a student of music, the cycle of fifths refers to a concept in music theory in which every subsequent musical note in a scale moving clockwise is a fifth away from the previous note. To a gastroenterologist, it may confer another more ominous concept that is a fundamental reason why wait times for colonoscopy will continue to grow.

There are few examples in contemporary medicine in which healthy people have been recommended to undergo surveillance procedures at intervals for the rest of their lives. Examples could include mammography and pap smears. Guidelines for screening colonoscopy are evolving, but a large percentage of the adult population could potentially be eligible on the basis of age, previous history of polyps, occult blood in stool or family history of colon cancer. In the case of a positive family history of colon cancer or in a patient in which polyps have been discovered, a cycle of colonoscopy may be initiated every five years on a lifelong basis. Thus, a new referral to remove a polyp in a 50-year-old woman may actually be a referral for eight colonoscopies until her death from other causes at 85 years of age. As these patients enter the waiting game for colonoscopy appointments, a clogging problem develops that is progressive and seemingly unending.

A new gastroenterologist begins a busy practice and, in the background, their colonoscopy practice is already building five years from their starting day (Figure 1). The wait times build depending on the number of available slots and the number of referrals. This is modelled for several scenarios (Table 1). The number of second colonoscopies after five years is reduced in the model because of noncompliance, death and relocation. However, as the new initial colonoscopies overlap with repeat colonoscopies, the number of slots available is greatly reduced. As a result, the wait times increase significantly after year 5 (Figure 2). This problem compounds for a second time at year 10 , when the number of available slots decreases again.

This problem becomes like a snowball rolling down a hill. The wait times continue to increase as long as the number of slots available is less than the number of referrals. There are no easy solutions to this problem. Hospital budgets are seemingly unable to expand existing endoscopy facilities to accommodate the increased demand for these services. Ambulatory endoscopy centres are developing, but gastroenterologists resent the lack of overhead fees that are enjoyed by other specialists (radiology, cardiology). There are many variables in the future that may affect this issue. These may include endoscopy by nonphysicians, technical fees to encourage ambulatory endoscopy, or replacement of surveillance by imaging techniques. Scheduling software could be used more effectively to allow physicians to titrate input to capacity. The real losers in this cascade are the symptomatic patients who face significant wait times, because apparently normal cases have beaten them into the queue. The gastroenterologist risks becoming a 'normoscopist' because all of their slots have been filled by repeat colonoscopy. Another approach may be to dedicate hospital

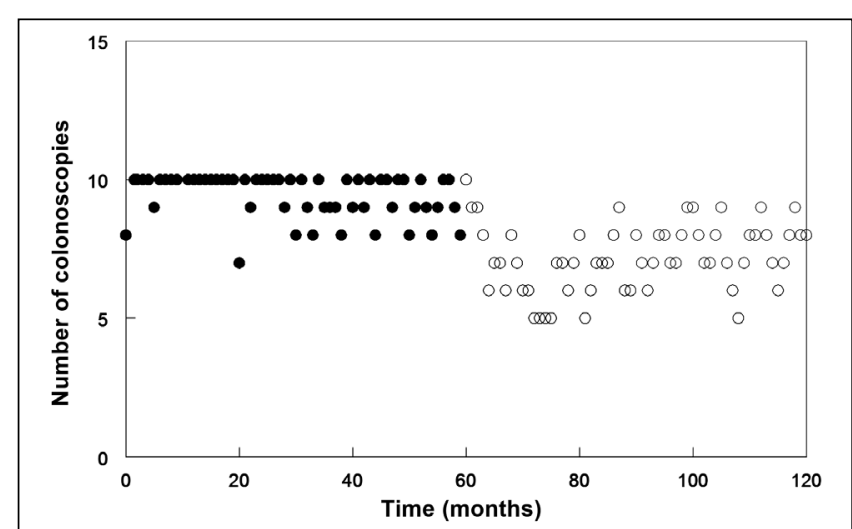

Figure 1) The effects on wait times as initial colonoscopy referrals $(\bullet)$ overlap repeat surveillance colonoscopy $(\circ)$

TABLE 1

Modelling scenarios to estimate wait times for a gastroenterologist with 10 colonoscopy slots per week

\begin{tabular}{lcc}
\hline $\mathbf{1 5}$ referrals/week & 20 referrals/week & 30 referrals/week \\
\hline 10 week 1 & 10 week 1 & 10 week 1 \\
5 week 1, 5 week 2 & 10 week 1 & 10 week 1 \\
10 week 2 & 10 week 2 & 10 week 1 \\
10 week 3 & 10 week 2 & 10 week 2 \\
5 week 3, 10 week 4 & 10 week 3 & 10 week 2 \\
\hline
\end{tabular}

For example, with 15 referrals per week and 10 slots available, five patients referred in week 1 are booked in week 2

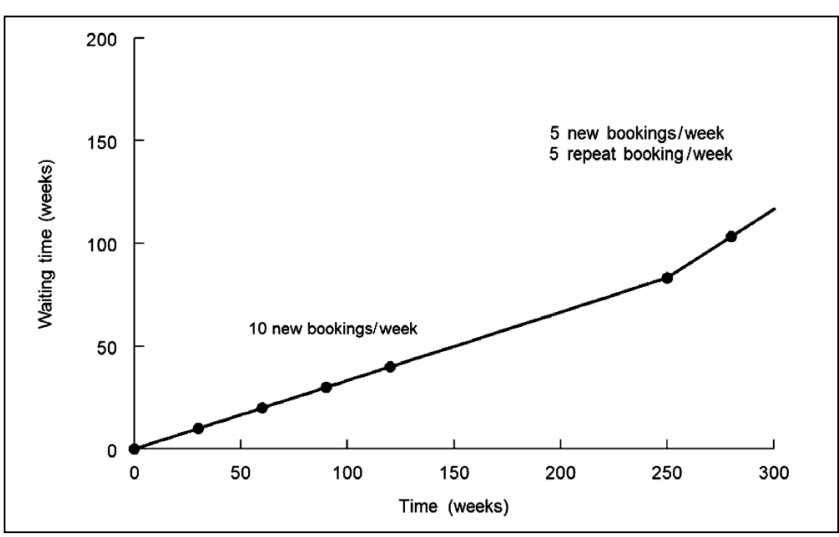

Figure 2) Effect of referral rate on waiting times. As initial colonoscopy bookings overlap repeat colonoscopy bookings, there is a marked increase in waiting times because there are fewer slots available for new bookings. This problem compounds at years 10,15 and 20

endoscopy slots to symptomatic patients, and follow-up cases to ambulatory endoscopy centres. As the ambulatory centre begins to clog, new centres need to be constructed. While this may be music to the ears of many gastroenterologists, there are significant financial hurdles before this could become a reality.

Department of Medicine, University Hospital, London, Ontario

Correspondence: Dr Paul C Adams, Department of Medicine, University Hospital, London, Ontario N6A 5A5. Telephone 519-685-8500

ext 35375, fax 519-663-3539, e-mail padams@uwo.ca

Received and accepted for publication May 26, 2008 


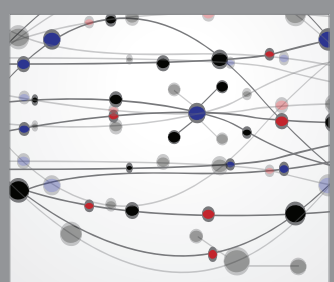

The Scientific World Journal
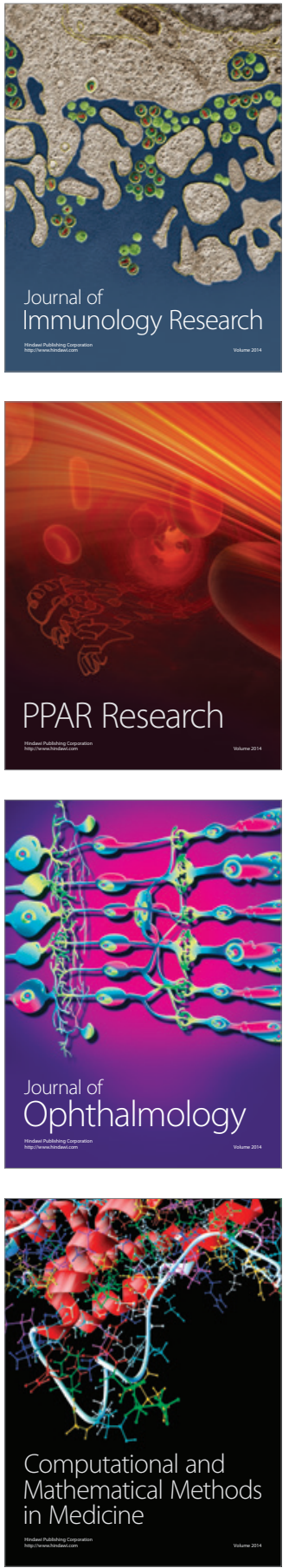

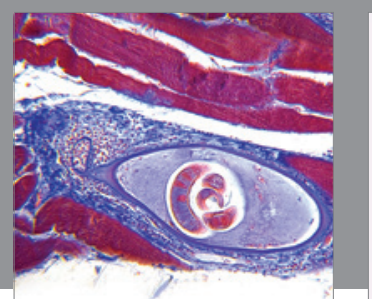

Gastroenterology Research and Practice

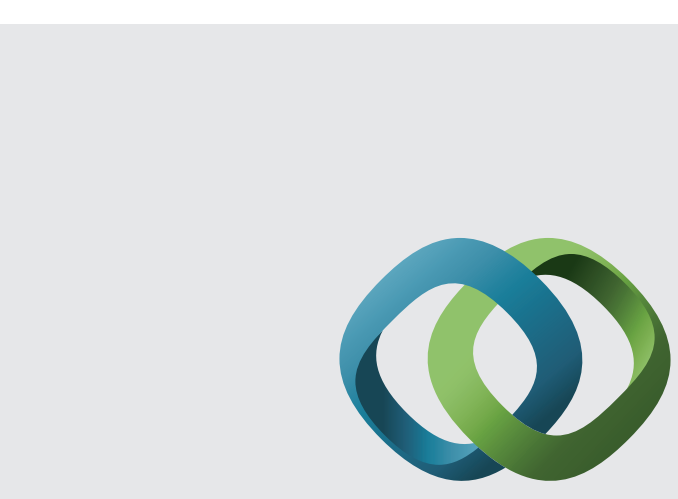

\section{Hindawi}

Submit your manuscripts at

http://www.hindawi.com
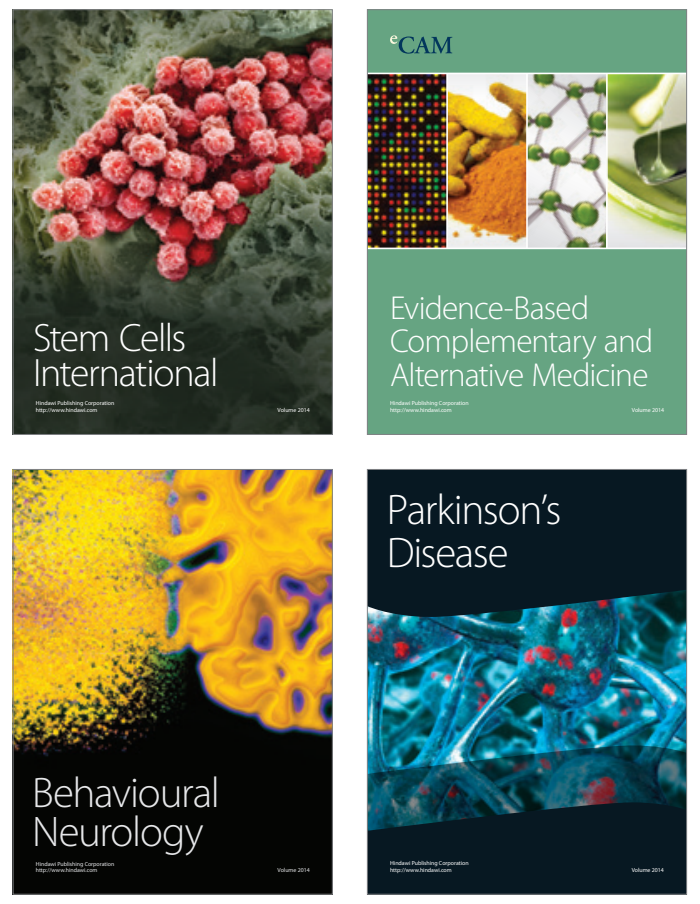
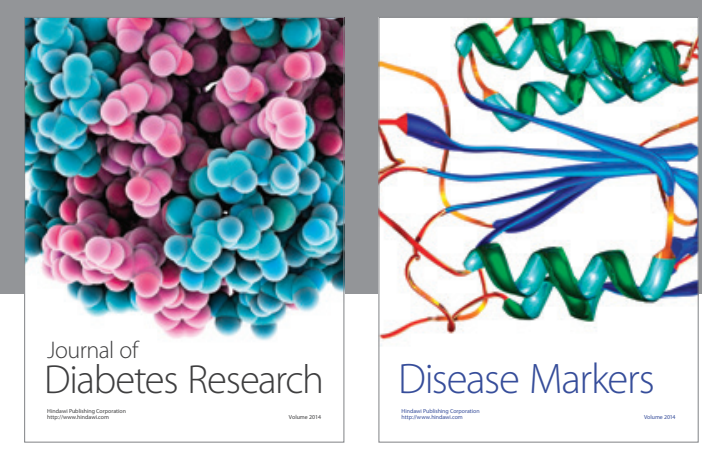

Disease Markers
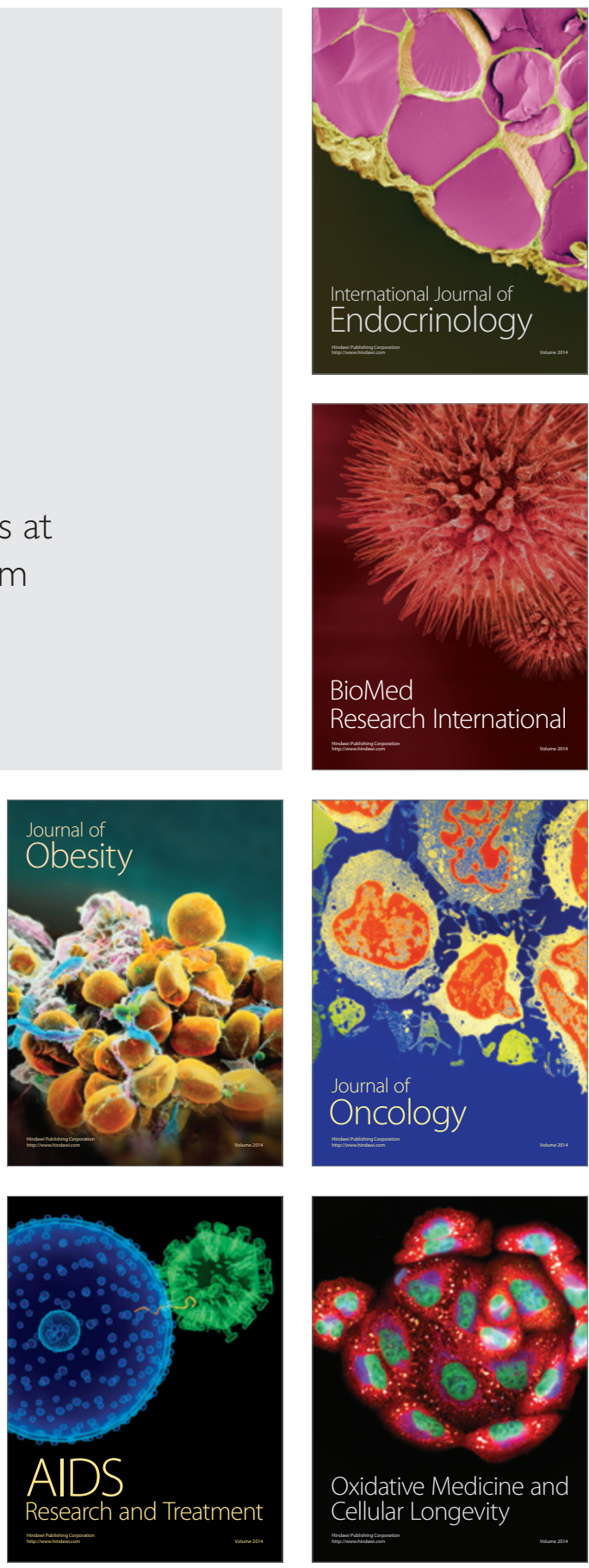